that every case must be judged on its own morits. When we produce a traumatic cataract as we do in needling for high dition or in needling for congenital cataract, we have a conprodion which resembles to some extent the traumatic cataract produced by injury from other causes. It is not a fact that vision will be lost quickly by an increase in tension and surgeon glaucoma; that is, there is ample time for the before to observe the condition and to perform his operation found damage of any consequence is done to the eye. I have found in my practice that if an increase in tension exists for from twenty-four to seventy-two hours the vision is not impaired, in the majority of cases, at least. It is my practice after I have produced traumatic cataract to remove the sion in twenty-four or forty-eigdt hours after inerease in tension occurs. Now it is also found that if we permit the lens substance to swell and become opaque its removal is more easily necomplished than if we attempt to remove the clear and substance. The adhesion to the capsule is not so great and we can whsh it out more easily. Consequently it las seemed to me that in all cases in which it can be done with safety to the patient it is better to wait until the lens sub. stance is somewhat opaque. It would seem to me the principle of removing the lens as soon after it has become injured as possible is rather a wrong principle to act on, but ench case, as I said before, should be treated on its own merits.
Increased tension that has existed for any length of time is of course dangerous to the cye.

DR. W. E. LAmbint, New York: My experience is much the same as that of Dr. Weeks. I have done quite a number of cataracts with high myopia. The indication for the removal of the lens in these cases has been dependent on the effect of the needling and the time after the traumatism has varied very much; but I think, as Dr. Weeks says, we cannot advise the immediate removal of traumutic cataract, but it must be removed when the condition of the lens makes it most favorable for extraction, by any metlod, washing out, etc. I ramember a case of injury in which a man was playing racquets. His glasses were broken and a large piece of glass had penetrated the eye. The late Dr. Bull and also Dr. Weeks saw the patient. I saw the patient within a few hours and detected a large piece of glass in the lens. The next day the l'ns began to be opaque, but the formation of the cataract was slow. The eye remained pretty quiet and by the advice of br. Bull we decided to wait a few days. Within two days, I think, after the accident the lens had swollen sufficiently to justify an attempt to extract the foreign body and wash out the lens. He advised very strongly against it and we waited. Six days after this symptoms of glaucoma set in rather severely, and I insisted that something be done or that some. body else take cliarge of the case. Quite an acute attack of glaucoma supervened. The extraction was done, the lens washed out and the man made an uninterrupted recovery and las to day $20 / 15$ vision in that eye. It is not always necessary to operate at once. I have had similar experiences with various cases of high myopia that $I$ have operated on, so that I think every cuse is to be treated according to the indications us they arise.

Dr. Eidar S. Thompsos, New York: It seems to me there are two very distinct points to be made in connection with br. the wovan's paper. 'The first is whether we get the case before the wound has healed up. By the time the inflammatory - reaction has set in and the original wound of entrance las healed, the question is of course $n$ different one. Any operation then will give a greater disproportionate renction than in the preinflanmatory period. If the inflammatory period has set in, then we will get a greater reaction. Whether removal is done in the first period or not depends on whether sufficient disturbance of the lens has occurred to cause swelling. If that has not occurred I think it is better policy to wait and not to subject the eye to the shock of the removal of the lens, because it undoubtedly. por se, causes a good deal of traumatic disturbunce. With regard to the effect of incrensed tension, I agree with Dr. Weeks thut increased tension is a very different matter from the increased tension in the glaucomatous eye and is not so serious. I think if we study the tonometer work for cqual measurements there will not be the sane reduction of sight in traumatic cases as in an equal time in glaucomatous cases. With regard to Dr. Donovan's cases, I take it that he sees them enrly and the lens is hashed up, and in such conditions $I$ would agree that we should immediately remove the caturact.

DR. J. A. DovovaN, Butte: The danger in any change from a woll-established method of treatment is of course that we become too radical on the other side. I favor getting most of these lenses out as soon as we can do so, but there are a grent many of them that it is not good policy to treat in this way at nnce. In some of these injuries one feels certain that there is going to be cataract, and it may not develop. One reason I give is that after the second day the swelling is so intense that nothing can be done. On the other land if there is any strong probability that the lens will not have to be removed I consider it best to wait. The general principle is that as soon as I am convineed that the lens should be removed, I remove it at the earliest possible moment, if $I$ feel it can be done with the greatest safety to the patient.

\section{DISTORTIONS OF THE VISUAL FIELDS IN CASES OF BRAIN TUMOR}

HARYEY CUSHIX(i, M.J., ANI) GEORGE .J. HEUER, M.D., BALTIBIORE (C'oncluded from pagc 208)

\section{ABS'IRAC'I OF DISCLSSION}

Dr. Submai Voorukes, Elmira, N. Y.: In two cases recently under my care in which decompression operations were done this interlacing and inversion of the color-field is present.

Dr. Hiram Woons, J3altimore: In reviewing these cases I find that there have been in most of them, in addition to the color-interlucing, certain symptoms that would at once lead the ophthulmologist to expect something else besides an ocular lesion. For instance, there have been one or two cases of Jacksonian epilepsy in this report, and various functional symptoms in various parts of the body, and these things themselves, in association with any field-abnormality at all will lead the ophthalmologist to consult the neurologist. On the other hand there nre cases in which we see color interlacing with optic neuritis, without any other symptoms. Now the orthodox interpretation of that has been loysteria, as we know. In the case of one patient whom .J believe Dr. Cushing subsequently operated on, I saw that interlacing of the color-fields without any other symptoms at all, without any optic neuritis, and made the dingnosis of hysteria from the absence of any other nerve symptoms at all. "Now a very practical question for us ophthalnologists to know about is this: When we get loold of eases with this interlacing of the color-fields alone, without any other synptoms on the part of the nervous system, how are we to interpret it?

Dr. Walticr S. Fraxklix, San Franciseo: Dr. Cushing said the fields seemed to vary with different observers, and I feel that here we lanve a chance to make nn improvement in our methods. The personnl equation enters largely into the taking of the color-ficld. Different men get a difference of 5 to 10 degrees with the same patient, and each fecls that his results are correct. Are there any particular details of taking the color-field, difference in style of perimeter, whether self-recording or not, or are there any details that Dr. Cushing can give us so that we can standardize our methods of taking correct perimetric measurements?

Dr. Jown w. Wroks; New York: Has this interlacing of the fields been noticed in conditions other than tumor, as, for instance, abseess of the brain; is it also characterized by interlacing of the fields? Is uny color but blue affected? Is the red field found interlacing at all with the green, or does it affect sinply the blue field in relution to the red?

Dr. Lewis S. Tinores, Los Angeles: How long does this interlacing of the fields persist? Is this symptom constant throughout the course of the development of the tumor, or does it become lost in the later stnges? We have had a very interesting case of cerebellar tumor here in this city the past winter. I male the diagnosis, but at the time I made it 1 was not satisfied that I lad true interlacing of the fields. 
The color-fields overlapped I believe, at only two points, but the case was very well developed at the time. The patient has been operated on since with very brilliant results. 'The patient was referred to Dr. Lobengier, one of our local surgeous. At the flrst operation he did not succeed in removing the eyst wall, but did so at the second operation. The two symptoms that brought this patient to me were hendache and vomiting. 'l'he young man had had an appendectomy, and a great many measures had been taken to relieve the headnches. lle had been East. At the time he consulted me the papillitis was so very well marked that the diagnosis was easily made. This patient was also seen by Dr. Orbison of this city who might acid something to the diseussion. But I am anxious to know about the interlacing of the fields because at the stage nt which I got this young man 1 was not satisfied that there was " true interlacing, thongh the fields were taken a great many times.

Dr. Hanis Crismo, Bultimore: I doubt not that we would have recorded this case that Dr. Thorpe speaks of as one of interlacing with one or two points. I would like to know how many points were taken. The slowing of some turning in of the blue field at the periphery in a patient with cerebellar tumor will be as much as we can expect. We cannot sulject these patients to very long detailed observation. Here the diagnosis is so delinite that it is hardly necessary to lay much stress on this condition which we hope may be of some use in the early stages when the papillitis, if we want to call it that, nay be present.

Jr. Woods' questions are a little diflicult to answer. There are of course many functional disturbunces, possibly sensory disturbances, that we do not recognize as anything else but funetionn, in people who may possibly have organic lesions. There are sensory disturbances as brought out by the twopoint tests which have an organic basis. These people with Jacksonian epilepsy have been patients in whom the lesion lius been certified, and they were people in whom one would have expected a sulliciently high grade of tension to have cansed un extensive choked disk. One of these patients-and this will nuswer again Dr. 'Thorpe's question-had had interlacing. ohserved over a period of a year, and the neurologists who land seen this patient, and many of us, were very much concerned nbout his eondition. We did not believe it was passible that he was harboring a tumor. He had had Jacksomian epilepsy', he never had any headache or gastric dis. turlunces of uny sort; in fact, no pressure symptoms such as we tsially consider, or in the past have considered, essential to a diagnosis of tumor. Jlis focal attucks persisted and becume so frequent that it seemed best to make an exploratory operation. and this cisclosed, as J reported in this series of eases, the largest one of the benign tumors that has oecurred in this serios of 250 cases (we lanve only spoken of 200 from the standpoint of the eye-ground). It weighed $198 \mathrm{gm}$.nhmost as large un the fist. Here was an individual who had wone a year with but little contraction of the color-field with this definite interlucing. and at many points. We may per laps tend to call eonditions interlacing of the fields which are not strietly so; possibly, endenvoring to make the matter renister, we ming have gone a little further than we were justj. lied in doing. fibe condition raries at diflerent times, lintigne may have somothing to do with this. The same person taking the field in the same individual, perhaps a few hours later or the next day, may register a dillerent field. But it shows this tendency, as a patient with indications of bitemporal hemianopsia may difler from day to day; the field assumes a somewhat different configuration, and it shows that one must generalize rather than particularize abont these conditions. I do not know how to interpret interlacing. We are rather inclined to interpret it as a mauifestation of pressure. It disnpeners, usually, before the eloked disk lias disappenred. I presume the persintence of the cluoked disk means that conditions have urisen secondary to the long-standing tension; conditions that lave set II) a reaction in the nerve, with round-cell infiltration, with new tissue formation, which lends to the persistence of the stasis and prevents the swelling of the nerve-hend from sulsioling rapilly. But there are propie without very moch change in the nerve-hend in whom the fields widen out and assume normal color relutions without any very evident subsidence at all in the choked disk.

In answer to Dr. Franklin's question, I, too, wish there could be a standardization of these matters. I have, perhaps, in what I have said, made some answer to the question. We use also a 0.5 disk with pure colors, and some of the fields with low vision must be plotted with $1 \mathrm{~cm}$. or larger disks.

There are other conditions, Dr. Weeks, that cause thisabscess, serous meningitis, ete. In not all of the 200 cases hits the tumor been certified, many, perhaps, not certifying until six montls or a year after decompression, when after a number of months the tunor has given evidence by producing neighborhood symptoms. Blue is the widest field, and possibly for that reason may be the field the restrictions of which are most seen. It does affect the other colors; sometimes the red is within the green, and the blue and red interlacing with the green field, but we have felt that we could get as much out of the blue and red periphery as if we took an extra periphery, and hesitating to give the patient a longer ordeal than necessary we have disregarded the green field.

I do not know liow long the interlacing persists. As I lane said in the paper, here is one that has persisted for a year, and the interlacing and the epilepsy were the only symptoms that the patient had, and shortly after the operation they had disappeared. This cerebellar ense I presume we would have regurded as one showing interlacing.

\section{Therapeutics}

\section{HEAT PROSTRATION ANI SUNSTROKE}

It is customary to divide the cases of illness due to excessive exposure to high temperature into two classes: one is distinguished as hent exhaustion; the other as sunstroke, or thermic or heat fever. It is important to recognize the distinction between these two classes of cases, as their treatment is entirely different and distinct.

Heat exhaustion is considered by many as a milder affection, although it frequently results in death. It may occur in those who are not exposed to the direct rays of the sun, but who are engaged in occupations which are accompanied by unusual heat, such as bakers, laundrymen, and foundrymen. It is associated with vasomotor paralysis. The beginning symptoms usually are dizainess, slight headache and throbbing in the hoad, nausea, and sometimes diarrhea; these symptoms increasing, the patient becomes cold, the skin becomes pale and clammy, great prostration ensues, the patient is restless, and may become unconscious. The temperature is usually subnormal, and is never elevated. 'The pulse is weak.

The treatment of this condition embraces removal of the matient from the influence of the excessive heat to which he has been subjected. If he has been out of doors in the sun, he should be immediately removed to the shade, and as quickly as practicable be taken into a house or to a hospital. He should be placed in bed in a r'oom which is cool and well ventilated. The clothing should be loosened so as not to interfere with respiration or circulation, and his working clothes should be removed, and hot applications, such as hot water bottles or hot bricks, should be placed around his extremities so as to restore the circulation and make him warm. If he is unconscious so that he camnot swallow, inhalations of ammonia should be given by the nostrils. Cold applications, either cold cloths or an ice-bag, should be made to the head; a mustard paste should be applied to the back of the neek and over the spine; and if the respiration is obvinusly impaired. a hypolermatic injection of $1 / 100$ of a grain of sulphate of atropin should 